\title{
DOCUMENTOS DE PASSAGEM
}

Mauricio Salles

Vasconcelos*

*vasconcelosmauricio@hotmail.com

Professor livre-docente (USP). Pós-doutor pela New York University, sob a supervisão de Avital Ronell. Dirigiu os videos Ocidentes (2001), Blanchot: Para onde vai a literatura (2005); Giro Noite Cinema - Guy Debord (2011); Uma árvore no Zaire (2014). Autor dos romances Telenovela (2014), Ela não fuma mais maconha (2011), e as narrativas Moça em blazer xadrez (2013) e Stereo (2002).

RESUMO: Este artigo analisa as estratégias narrativas de senvolvidas pela filmografia de Chantal Akerman, enfatizando a articulação entre corpo e cultura. Põe foco no diálogo promovido pela diretora com as transformações históricas ocorridas desde os anos 1970, na criação de diferentes formas e estilos cinematográficos.

PALAVRAS-CHAVE: Corpo, cultura, movimento.

ABSTRACT: This article analyses the narrative strategies developed by Chantal Akerman's filmography emphasizing the articulation between body and culture. It puts focus in the dialog promoted by the director with the historical transformations when they took place from the 1970 years in the creation of different forms and cinematographic styles.

KEYWORDS: Body, culture, movement 
Desponta no cinema de Chantal Akerman, desde as primeiras produções, um sentido conjunto de testemunho e experimentalismo, indissociável dos intercâmbios contínuos promovidos por documento e notação pessoal. Formula-se, a partir dos anos 1970, uma filmografia timbrada pelo caráter de passagem, à altura de um corpo feminino que se exibe, deixando-se mesmo fixar através do jogo composto de autoria e ficcionalização. É o que ocorre em Je Tu Il Elle, filme onde a própria Akerman depõe e atua, simultaneamente, como intérprete de Julie, chegando a se assinar na ficha técnica com o nome da personagem. Um corpo que realiza trajetos - flagrado de um modo evidente no filme citado, de 1975 -, sob o compasso de um empenho físico e um dimensionamento espacial, francamente exposto à confissão e à nudez, mostrando-se, contudo, capaz de assinalar sua localização na cultura, de modo a configurar um estado reflexivo-situacional.

Inicialmente, observa-se em sua filmografia um grafar-se, como se fosse incorporado um dispositivo escrito coetâneo com a projeção, vocalizado na gradação de diários íntimo dados à leitura (quando não, por meio de cartas familiares, reveladas em off, durante os percursos feitos em Manhattan, como se ouve e se vê em News from Home). Marca-se, então, por escrito uma bem definida perspectiva de subjetivação no modo de filmar e compreender o momento pelo qual passa o cinema. Simultaneamente, gravam-se, com toda uma disposição lenta e minuciosa tomada pelo desenrolar da película, cerimônias (como já podia observar Deleuze, em ImagemTempo) estritas de gestualidade e liberação somática, estratégias de sensibilização no que se refere às ações e às presenças, próprias do feminismo.

$\mathrm{Na}$ consecução de um projeto fílmico, compreendido no correr do tempo, no qual a transparência de suas formulações teóricas e culturais estão no cerne da construção das formas visuais, colhidas tanto no cinema-verdade quanto nas diferentes iconografias/instalações obtidas pela esfera plástica na contemporaneidade, ergue-se uma tópica sinalizada pelas migrações de povos em correspondência com o remapeamento da geopolítica global. Emerge o que pode se chamar de cultura do nomadismo, em toda sua atualidade e variedade, a envolver os territórios mais diferenciados, dos mais desertificados aos ultraurbanos.

Passagem - o cinema incita uma constante auto-posição de linguagem, no andamento de suas células motoras de registro e elaboração da realidade, sob a dinâmica direta do movimento. Em consonância com a inserção de corpos testemunhados em primeira pessoa - como se efetiva em Je Tu Il Elle -, modulam-se as variantes coletivas dos filmes mais recentes, caso de D'est e De l'autre côté, captadas em itinerâncias 
e viagens, em grandes deslocações cotidianas, já numa abrangência populacional.

\section{FORMA-DIÁRIO}

A começar da participação da cineasta como protagonista e do fator escrita preponderante no modo de encaminhar a enunciação da fala, assim como na captação da postura meditativa de alguém, em espaço privado, posto em desnudamento e confissão, o projeto declaradamente autobiográfico de Je Tu Il Elle apresenta seu traço mais pulsante na dimensão aporética contida em tal forma escritural. Como analisa Manue de Freitas, no livro Me, Myself and I, dedicado à produção poética do português Al Berto, a reivindicação do "nome próprio" (da experiência do ser mulher como uma prática particular em primeira pessoa, acrescente-se) no trato com as palavras diz respeito, também, ao impasse, à inviabilidade de serem demonstradas categorias como "verdade", "autenticidade" ou mesmo "sinceridade" (Freitas, 2004: 22).

Observa-se, nesse sentido, como as marcações enunciativas da voz, asseguradas pelo ato da escrita, se fazem a um só tempo por deslocamentos e desaparições da presença de Julie (C. A) no espaço de um apartamento (e poderiam ser quartos, cubículos de morar, como se dá em La chambre e L'homme à la valise). Correspondem-se, pois, a uma variação do corpo que a construção confessional procura dar conta, imprimindo um estilo mais afeito à erotização do feminino, com todas as dobraduras do físico de uma mulher em célula cerrada, do que propriamente à manifestação feminista de um ideário transposto à esfera cinematográfica. Tanto é que Julie, a protagonista, assume um discurso em primeira pessoa, mesclando-se, em seguida (já fora da clausura da moradia, lançada a uma rodovia), com um segundo/outro (um homem que se põe a confessar, a tomar a palavra) até encontrar-se com um ela (à qual se integra, num ato pleno e visível de sexualidade) em um novo apartamento, onde pode se fusionar e se desgarrar de uma única perspectiva pessoal-pronominal, irresolvivel enquanto composto de eu, ele e ela.

Realizado no contexto de militância do feminismo, o filme de 1975 se posiciona em direção ao ensaio (em torno de uma mulher, no próprio corpo da diretora), a um estudo no qual atitude e observação se conjugam. No entendimento gradativo da forma-diário como plataforma e plano reiterado dos atos que envolvem a protagonização de Julie, ocorre o que outro poeta concentrado nas questões dispostas pelo estilo autobiográfico, caso do norte-americano Charles Olson, considera como autoação.

Olson não desvincula o texto produzido na primeira, singular, pessoa de um conhecimento experimentado a cada gesto proveniente de uma individualidade em formulação. Enfatiza, pois, a condição material da linguagem como dado 
co-presente do eu em desvelamento, extensivo às demais possibilidades do real. É o que apreende o poeta, também americano, Robert Creeley em seu estudo sobre o estilo autobiográfico (Creeley, 1998). Entendido como eixo do processo confessional, o diário enquanto espaço/plano (do modo como tal prática exerce função central na escrita de um autor contemporâneo de Akerman, como é Al Berto) oferece da maneira mais pronunciadamente crítica o limite do vivencial, contrariando sua compreensão como instância pré-formada, dada de forma espontânea, não-mediada. Fornece uma dinâmica oposta a uma tese, a uma consideração abstrata acerca do eu como uma categoria prévia à ação pela escrita. Muito ao contrário, o diário, tomado como pólo recorrente da narrativa fílmica, deixa aflorado um corpo em flagrante e choque com as noções conhecidas de um sujeito puramente testemunhal. Pois é observável uma postura de atrito entre voz e ato, entre o escrito e o tato constante da autoimagem da mulher que filma, a contar de uma idéia de si na conjuntura de um tempo presente, favorável ao depoimento de gênero (tendo-se em conta a individuação emergente na história, reivindicada em primeira pessoa).

Justamente por estabelecer o vínculo de um eu com a sucessão é que Creeley, em diálogo com Olson, acirra a contraposição ao constructo do cogito - fundamento da ratio ocidental -, quando nota o dado do ser pensado como essencial à emergência intelecto-sensitiva fomentada pelo diário, uma vez que se dá como registro e processo

simultâneo de elaboração/criação. Não à toa, Akerman extrai dessa forma menor,

secreta, de escrita uma compreensão de sua circunstância como mulher no tempo, concebendo-a de um modo apropriativo, sempre tático, muito afeito ao que formula a filósofa Avital Ronell como feminização do mundo. A forma-diário, recepcionada como documento, viabiliza ao percurso de C.A no cinema (já na gênese de um trabalho que procede em constante mutação) uma outra diretriz para a dimensão do narrado, para o testemunhado. Possibilita que se tornem as anotações pessoais condizentes com o mundo feminino, todas as afecções - "não estou conseguindo expressar minha ternura, minha ternura, entende?" (poderia dizer a brasileira Ana C. ou A.C. quase num jogo anagramático com C.A, também outra contemporânea sua na escrita em primeira pessoa e no advento da mulher na cultura, atenta ao potencial transformador dos sentimentos e da sensorialidade na arte, tomada pela comunicação e sua impossibilidade mais básicas) -, um modo do autor ser observado e atuar nas dimensões mais divergentes. Proporciona curiosamente um outro em emergência, como se facultasse um fio de narratividade a ser seguido como o desdobramento gradual de um documentário ou de uma ficção concentrada naquilo que Starobinski, em 
L'oeil vivant, podia apreender como o alcance de um ponto em que o autor de um texto, o produtor de imagens, não mais refletiriam (sobre) suas realizações, mas tornar-se-iam olhados.

O dado do não-saber (seminal para a produção artística e filosófica contemporâneas, como bem estudou o ficcionista Donald Barthelme), trabalhado pelo cinema para além da visão imediata obtida por meio do simples suceder de takes, ordenados segundo uma roteirização, se impõe de modo crescentemente claro para Chantal Akerman. Apresenta-se como um desafio na criação de diferentes filmes, sejam os engendrados como um testemunho ou confissão, quando não é o caso daqueles estilizados como narrativa de ficção, como também os que se embasam na documentação em bruto, mais direta, do real.

C. A parece não se desligar da noção de que a autoação é norteadora dos módulos todos de registro e estilo presentes em sua filmografia, assimilando da captura das imagens o traço processual do conhecer como inerente à deflagração da ótica no feminino, no singular, que orienta todo seu cinema, a partir de Je Tu Il Elle, longa de estréia. Uma ativação contínua se dá na história das últimas décadas - de um século a

outro -, sem que se perca uma espécie de fulcro ambivalente em torno do qual vêm se potencializado os filmes da diretora - dos mais curtos aos silenciosos, daqueles captados como uma paisagem ou a passagem de um flagrante até os mais próximos de uma narrativa constituída, centrados numa ficção, num certo traço de relato (por vezes concebidos como um musical, senão tangenciando a construção de um romance). "Fazemos o que sabemos antes de saber o que fazemos", considera Olson sobre a conjunção das formas de escrita do eu e a linguagem (apud Creeley, 1998: 40). A provocação do axioma lançado pelo poeta move tanto o itinerário da diretora (com a marca, inclusive, de busca, de pesquisa, de viagem) quanto a problemática mais íntima referente às formas, ao modo de registro e projeção do cinema.

\section{MUSICAL/ROMANCE}

Nos filmes iniciais, curtos ou não, assim como nos atuais, há um leitmotiv cênico que não se abandona - mulher e valise. Mulher em viagem - Fotograma flagrante da mobilidade, de um errar disseminado como topos cinematográfico dos 70 aos presentes 2000 , desdobrado em um traço espacial a se reiterar como num contraponto/contracampo - mulheres em diferentes quartos, dos hotéis (como a incursão por Hote Monterey podia indiciar, num misto de Warhol e Snow) a provisórios apartamentos (Lá-bas). Entre um desempenho testemunhal (caso do primeiro longa), favorável ao insulamento, à concentração sobre si para a elaboração de um relato (diário/carta) e o trânsito profissional por cidades desse mundo (como são descritas as realizadoras cinematográficas 
de News from Home e Les rendez-vous d'Anna), as figuras do feminino são apreendidas. A cineasta belga sinaliza com ambiguidade a condição de cativa (evidenciada na versão de Akerman para um dos títulos

da recherche proustiana) da amorosidade e dos códigos conviviais contemporâneos, no que diz respeito à mulher nos diferentes títulos de sua filmografia, ora por um sentido calculado, ora por um modo desabrido, de busca ou de fuga sempre através de uma deambulação. Configura-se de uma maneira nada coesa, pouco discernível, o trato das dimensões privada e coletiva referentes às imagens e aos corpos femininos. Nos filmes mais narrativos, entretecidos pela dinâmica do romance - dos encontros de amor mesmo - pode-se notar, surpreendentemente, uma combinatória heterodoxa de objetividade e distanciamento analítico, consonante com a perspectiva documental.

Um certo/outro documento se faz em estudo e, ao mesmo tempo, em ação. Escrita e captura fílmica se dão em troca intermitente. Uma noção cinemática do roteiro concebido como linguagem, por sua materialidade composicional, antes de ser uma técnica funcional das ações e das descrições, incide de modo patente como uma construção textual que não se deixa facilmente aderir ao plano físico dos personagens, produzindo um intervalo entre a mentação e o ato.
Curioso é observar, na esfera de filmes conduzidos pelo relato, pelo romanesco, a abertura de um plano off reservado à voz e à música. $\mathrm{O}$ que poderia resultar como ênfase do propósito aparentemente ficcional por meio do reforço dado à vocalização de uma narradora (Nuit et jour) e à entourage fantasista de um musical (Les années 80; Golden Eighties e mesmo o que faz de Toute une nuit uma verdadeira ciranda de afetos em andamento melódico) acaba por proporcionar uma gradação inusitada de documentalidade em torno do universo afectual, interrelacional, descrito através de mulheres e homens em intimidade.

Notável se mostra, em Nuit et jour (1991), o poder de in trospecção causado pelo foco narrativo vocalizado, simultâneo à dimensão de análise e investigação acerca das vivências sexuais de Julie (de novo, o nome passe par tout de mulher adotado por Chantal A., dessa vez apenas atrás das câmeras a comandar a direção da atriz Guilaine Londez). Recorta-se do trânsito da protagonista entre o apartamento onde vive com Jack e a rua, seu vínculo com a cidade e a noite, propiciado pela relação amorosa mantida paralelamente com Joseph (motorista, no turno do dia, do mesmo táxi guiado por Jacques à noite). Justamente, o elemento de passagem pela cidade, na noite, compassado

pelas intervenções descritivo-narrativas de um off no feminino, acaba por favorecer o potencial de flagrante e 
observação presente no comportamento desreprimido, na liberação sexual de personagens pontuados por intervalos de reflexão, de comentário (com outra voz).

A música desempenha, por outro lado, um papel de interrupção e distanciamento da ficcionalidade pregnante desenhada pelo roteiro escrito por Pascal Bonitzer (crítico e realizador) em parceria com a cineasta. Música, no mais das vezes, cantada ou cantarolada por Julie, numa apropriação de uma possível trilha sonora, de um convencionado pano-de-fundo melódico tecido por um filme de amor, intenso e irrefreado como é o caso de Nuit et jour. O canto produz então, um efeito tanto de celebração espontânea do amor noite-e-dia vivido pela pequena heroína urbana quanto um corte, uma intervenção, no que se refere ao plano ocupado pela voz da narração e pela música que vez ou outra toca, sem a mera função de preencher espaços vazios.

O cantarolar desenvolto de Julie, no dia-a-dia (na noite e no dia), em seus trajetos pelas ruas (pelo menos em um momento, substituindo-lhe as palavras), frisa o intuito de ser deslocado para um plano direto, sem intermediações, o lugar de fundo ocupado pela música nos filmes. Da mesma forma, o artifício da narração (mulher em off) só se torna plausível, tendo-se em vista a manifestação espontânea das vivências a livre exposição afetiva da parte dos personagens, enquanto alcance de um dimensionamento de investigação integral obtido pelo cinema de Akerman. No universo da ficção, interessa-lhe flagrar a minudência das motivações (vindo daí o off narrativo) no instante em que os personagens mais se entregam ao ato impulsivo, cego, dos sentimentos, para além da imediaticidade do que vivem e dizem estar vivendo, como se submetessem a um foco de abrangente de análise. Na mesma voltagem, a cineasta tem em mira as fantasias, os devaneios e as projeções que a música ouvida, em Nuite jour (pela voz da protagonista polarizando-se com alguns entrechos sonoros executados), acaba por irradiar como um dado amplificador da realidade do trio amoroso. Amplificação sonora da idéia mesma de realidade e do lugar submetido à música nos filmes. Tal raio de expansão se refere, também, à presença de um (a) narrador (a), como é o caso, posto em diálogo e pacto explícitos com os personagens no momento em que eles mais se põem em ação, oferecendo-se sexualmente sem anteparos ao mais próximo, da noite ao dia desprovido de intervalo, tentando refletir sobre os acontecimentos no calor das sensações experimentadas.

Não por acaso, o díptico Les années 80 (1983)/Golden Eighties (1986) potencializa a compreensão da penúltima década do século XX em torno do que pode se conceber como uma visão musical do mundo. Juntamente com a incorporação de um número extenso de personagens - iniciada com Toute une nuit (1982), filme, aliás, construído sob a andadura 
de diferentes registros sonoros -, apresenta-se como inaugural no cinema de C. Akerman a musicalidade como forma de narrar e apreender modos de ser em comum.

Em correspondência com a execução, a concepção musical dos filmes, é exercida uma crescente mobilidade dos corpos em ação (por puro impulso das sensações) e atitude reflexiva. Através da aceleração dos movimentos - danças, deambulações, gestos de fuga e de busca - se unem diferentes personagens, travando-se assim formas de ligação com uma coletividade de sujeitos em um andamento incapaz de obliterar suas pulsações mais urgentes, assim como seus pontos menos visíveis de tensão, de impasse no encontro com muitos e diferentes outros, envolvidos numa semelhante procura de contato.

Não se pode esquecer a ressurgência das canções nos anos 1980, sob a aliança dos vários estilos pop, em efervescência, com a imagem videográfica. O clip passa a ocupar um lugar não apenas de comercialização da indústria fonográfica, mas estende seu dínamo estético e narrativo em tempo breve para o espaço cinematográfico. De Godard a Korine, do filipino Brillante Mendoza ao mais recente Reichenbach, todos incorporaram de alguma forma o constructo portátil-cinemático da música como modo de montar o espaço-tempo narrativo na gradatura das mais novas afecções e atitudes culturais, comportamentais.
Akerman dá testemunho desse momento da história ao explicitar seu elo com o music-hall de canção e imagem coroado por cápsulas sonoras/narrativas como o clip, em variações que repercutem em nossa temporalidade microinformática/milenar. Corpo e tecnologia móvel (visual/musical) só fazem intensificar o irrompimento perceptível no final de Nuit et jour, no qual se afirma o posicionamento ético-sexual celebrador de Julie, entregue à sua solidão e lançada, a um só tempo, ao movimento da cidade numa espécie de culminância. Portando sua valise, o personagem feminino surge à maneira de um fragmento ficcional da contemporaneidade cinematográfica: um corpo da música que extravaza por todos os lados, por todas as ruas, com a dimensão de uma réstia de épica, através da qual sua história pessoal se deixa flagrar como um documento de passagem.

\section{ALEA}

Em seu texto "A caminhada aural" (1994), Iain Chambers já podia apontar os elos formados entre subjetivação e deslocamento. Em torno do walkman, aparelho desdobrado na atualidade em incontáveis acoplagens portáteis de telefonia, arquivos de imagem, texto e som on-line, só se tornam mais acentuados os traços apreendidos por Chambers a respeito da mobilidade envolvendo tecnologia e a emergência de um ethos multiculturalizado referente à ruptura da divisa centro-periferia, entre diferentes territórios mundiais. No 
vínculo que se cria entre transnacionalidade e mundo tecno, de acordo, também, com as leituras de outros estudiosos da cultura global, são favorecidas atuações simultâneas na partilha de um pertencimento coletivo, marcado pela assimetria, pela complexidade das interrelações, tendo no horizonte a velocidade dos registros e arquivamentos informáticos em consonância com uma diversificada, presentificada, formação populacional, multitudinal em tempo real. Não à toa, Chambers trata da world music no emergente cenário da mundialização.

O filósofo e historiador da cultura põe em relevo a perspectiva da individuação, sintonizada na livre escuta de uma trilha sonora em andamento móbile (considerando-se o foco de sua análise concentrado no walkman), como um recorte feito nos espaços em que percorrem muitos outros corpos em reconfiguração dos lugares de trânsito, lugares em comum, pontificados, como diz Chambers, pela modulação das identidades, pela hibridez dos contatos. Não por acaso o autor de "Mundo partido: centro de quem, periferia de quem?" cita Richard Kearney: "a noção de sem-teto e de migracão comparece como a condição irrevogável da cultura mundial (apud Chambers, 1994: 82).

O fato de Chantal Akerman realizar o projeto D'est (1993), antes de se tornar filme, como uma instalação exposta em museus da Europa, viabilizada por uma panóplia de dispositivos visuais típicos das novas tecnologias digitais, não se dissocia da matéria investigativa que norteia seu mapeamento da Alemanha, Polônia e Rússia quando da desintegração do antigo bloco soviético às portas da unificação da Europa Ocidental. Passível de ser resumido como uma instalação multimédia centrada na União da Comunidade Européia, D'est deixa de se alinhar a um mero produto mecânico-causal das evoluções tecnológicas do cinema assim como não celebra o simples coroamento globalizante da dissolvência de um pólo geopolítico mantido, até início dos anos 1990, na contracorrente da transnacionalização do capital.

Atenta ao que Chambers poderia definir como "politica das transfigurações" (1994: 82), assimilada em correspondência com conjuntos e formações coletivos não-lineares, desproporcionais, atonais mesmo, utilizando-se a nomenclatura musical de que parte o pensador de Migração, Cultura, Identidade para relacionar as novas conexões mundiais e os povos, Akerman não se pauta pela tentativa de mostrar a desintegração de um sistema, coordenando assim uma visão com suas próprias noções preconcebidas. É o que se pode ler no testemunho produzido por ela acerca da realização da instalação-filme. O foco se volta para

Tudo o que está mudando pouco a pouco - os rostos e as paisagens (...) Países que compartilham uma história comum desde a guerra (...) iniciam agora caminhos diferentes (...) vozes que 
contarão histórias importantes ou insignificantes (...) que de algum modo captaremos como a música de uma terra estranha, só que mais familiar. (AKERMAN, 1996: 18-20)

Há precisão no comentário feito ao projeto D'est por Kathy Halbreich e Bruce Jenkins, para além de sua redução ao propósito operacional, técnico e sintetizador da media eletrônica. A "captura do fascínio original do cinema pela vida em movimento" (1996: 7) centraliza as atenções da diretora. E como se a mudança política observável em voltagem global conduzisse o olhar de Akerman para a convivência com a paisagem humana dos povos do Leste através de uma lógica da mobilidade, obtida por meio da viagem, da experiência de quem filma e passa por um cruzamento de olhares, tão significativo nesse filme sonoro, destituído porém de testemunhos verbais. A tecnologia dinâmica, portátil, característica do cinema da época da pós-produção orienta a cineasta contudo, para uma perspectiva posteriorizada em relação qualquer quadrante/enquadramento, na qual o dado do tarde demais - tomado do fim de certa história do século XX - possibilita um registro a contrapelo das intenções documentais de um painel, de uma tese. Como bem assinala a própria Akerman aquilo que se busca acaba por ser encontrado, " manipula-se as coisas em excesso para encontrá-las”(1996: 22).

Traçando um elo visível com seus primeiros filmes no que toca a autoação, o movimento autoindagativo de quem se põe em sincronia com as atitudes vindas dos corpos em viagem, em deslocação imprecisa, o cinema emergente em D'est dá atualidade a uma espécie de documentação originada dos atos de caminhar (entre as multidões) e esperar (a manifestação individualizada dos rostos, dos olhares).

Rostos enquanto se isolam da massa, expressam algo todavia intato e contrário à uniformidade que por vezes chama a atenção nos movimentos de uma multidão em seu exterior, o contrário também de nossa própria uniformidade. (AKERMAN, 1996: 61).

Nítida se mostra, em D'est, uma investigação em divergência com os documentários preparados, uniformizados em sua gênese pelas marcações ideológicas dos diretores e dos universos humanos a serem entrevistados, que resultam em projetos previsíveis no seu alcance crítico e testemunhal antes mesmo de serem assistidos. O documentarismo construído nesse filme de início da década de 1990 se apresenta como desbravação de um campo-de-forças, desde o que abarca sua materialidade de linguagem, situada na fronteira entre a tomada em bruto da exterioridade das ruas, das populações, e os registros da intimidade, da vida doméstica das povoações européias do Leste, até o que diz respeito a outras fronteiras - para além da mesclagem entre cinema-verdade e foco ficcional -, aquelas de teor histórico-cultural, que acabam 
por narrar a própria trajetória de Chantal Akerman dentro e fora do cinema.

Guiada por uma concepção alea do documental - por meio da tomada direta, orientada pelo movimento urbano, multitudinal, caso de D'est, ou, como acontece em Là-bas (2006), sustentada pelo uso da câmera fixa, direcionada ao léu de uma câmera/câmara aberta às vozes de um apartamento na fronteira de um outro (frontal) prédio entre janela e persiana, ao acaso de uma estadia em Telaviv nesse início de milênio em conflagração -, a diretora se posiciona no eixo do acontecimento, no pólo máximo do conflito histórico em processo, em descontinuidade. Dentro da história real e seu off - por meio do atrito criado nas ruas ou no recuo da vivência pessoal.

Depois do comunismo e do abalo ao império americano em suas extensões judaico-palestinos, no seio da problemática da globalização, C.A não deixa de frisar sua inserção nada unilateral na história e na cultura, quando se observa sua origem semita redimensionada pela vivência internaciona de cineasta para além dos domínios europeus. É o que se vê em Lá-bas por meio da recusa do part-pris de qualquer fundamentalismo, de uma imobilizante e "datada" tomada de posição, ao tornar o alea cinemático, no que tem de básico e instrumental o aparelho em movimento, uma forma de ingresso a planos fronteiriços, entre o prisma da domesticidade e o flagrante do povo israelense em seu cotidiano, ao acaso, no clamor mundializado dos conflitos geopolíticos. O mesmo se observa em De l'autre côté (2002), no que se refere à fronteira México-Estados Unidos. Curiosa e comovente, se mostra a perspectiva alcançada, no final, com a enunciação de um relato em torno de uma mãe mexicana e seu filho perdidos nesse trânsito de identidades, de cidadanias. Uma narração feita pela voz da diretora ocorre, então, numa revivência confluente, mas nada unidimensional, com o início de sua filmografia (Je Tu Il Elle e News from Home), atualizada por uma alteridade essencial, crescente, para fora de uma demarcação identitária.

De fato, os filmes de Chantal Akerman se fazem ver grafar como passagem, tendo-se em mira diários e documentos construídos sob o signo da experiência, pontuados pelo fluir/refluir de corpos compreendidos tanto em procedimentos de subjetivação quanto na dinâmica da migração, da multidão. Mas, talvez, seu ponto mais intrigante esteja na história cultural que os envolve, em atenção ao decurso das últimas três décadas, a contar do refluxo da idéia de revolução, testemunhado nos filmes dos 70 através da coroação da ótica minoritária. A partir das configurações dos corpos registrados em atos e estratégias transformadores da noção de sujeito na história, até o presente contexto milenar, marcado pelas erosões totalizantes, indiciadoras, contudo, de 
novas conjunções com a globalidade e o redimensionamento de múltiplas, amplificadas relações com diferentes culturas e formas de vida, o cinema e sua autora se deixam documentar. Reside nesse conjunto de imagens e testemunhos polivalentes uma modalidade insuspeitada de aprendizado com o corpo e a cultura. Vem daí um potencial renovador de entendimento do tempo e do lugar desempenhado pela criação no cinema. Um fluxo de rostos, paisagens e registros sonoros/vocais se engendra, no passar de um século/milênio a outro, através de uma combinatória fascinante de poética e política, de voz interior e disseminação na vida imediata.

\section{REFERÊNCIAS}

BARTHELME, Donald. Not-Knowing. Nova York: Random House, 1997.

CÉSAR, Ana Cristina. Correspondência completa. Rio de Janeiro: ed. da autora, 1979.

CHAMBERS, lain. Migrancy, Culture, Identity. Nova York e Londres: Routledge, 1994.

CREELEY, Robert. "De adentro hacia afuera. Apuntes sobre el estilo autobiográfico". Lo creativo y otros ensaios. Trad. Patrícia Gola. Cidade do México: Universidad Iberoamericana/Artes de México, 1998. p. 35-51.

DELEUZE, Gilles. A imagem-tempo. Cinema 2. Trad. Eloisa de Araujo Ribeiro. São Paulo: Brasiliense, 1990.
FREITAS, Manuel de. Me, Myself and I. Autobiografia e

imobilidade na poesia de Al Berto. Lisboa: Assírio \& Alvim, 2005.

HALBREICH, Kathy et alii. Rozando la ficción: D'est de Chantal Akerman. Trad. Ferran Estellés e Anna Montero. Valencia: IVAM, 1996

RONELL, Avital. American Philo. Entretiens avec A. R. Paris Stock, 2006.

STAROBINSKI, Jean. L'oeil vivant. Paris: Gallimard, 1961. 